\title{
Arquitectura y decolonialidad: algunas ideas sobre la Escuela de Artes Plásticas de Ricardo Porro
}

\section{Architecture and decoloniality: some ideas on the National School or Plastic Arts by Ricardo Porro}

\author{
Yasser Farrés Delgado \\ Facultad de Filosofía y Letras, Departamento de Filosofía, Universidad de Zaragoza. \\ Zaragoza, España. \\ yasserfarres@gmail.com
}

\begin{abstract}
Resumen
Las Escuelas Nacionales de Arte son un conjunto arquitectónico paradigmático del llamado "período romántico" de la arquitectura de la Revolución Cubana. Este momento estuvo marcado por la búsqueda de una arquitectura apropiada a las circunstancias de aquel país en tanto estado poscolonial. Entre las edificaciones que definen al conjunto, destaca la Escuela de Artes Plásticas, del arquitecto Ricardo Porro, por su particular simbolismo. Este artículo interpreta dicha obra desde una perspectiva decolonial y argumenta su valor como una alternativa a la colonialidad arquitectónica actual.
\end{abstract}

Palabras clave: colonialidad, arquitectura, estética, Cuba, Ricardo Porro.

\begin{abstract}
The National Schools of Arts are a paradigmatic architectural ensemble from the known "Romantic Period" in the Architecture of the Cuban Revolution. This moment was characterized by the search of an appropriate architecture according to the circumstances of this country as Postcolonial State. The symbolism that Ricardo Porro granted to his buildings is remarkable, particularly in the case of School of Plastic Arts. This paper aims to interpret that building from a decolonial perspective and demonstrate its value as an alternative to the current architectural coloniality.
\end{abstract}

Keywords: Coloniality, Architecture, Aesthetics, Cuba, Ricardo Porro. 


\section{Introducción}

Las Escuelas Nacionales de Arte (ENA) constituyen uno de los conjuntos arquitectónicos paradigmáticos del llamado "período romántico" de la arquitectura de la Revolución Cubana -o "romántico y surrealista”, según Roberto Segre (“Los años 60” 32)-. Este período, que podría delimitarse entre 1959 y los primeros años de la década de 1970, cuando comienzan a notarse en la arquitectura y la ciudad "los efectos de la misma política cultural rígida e impositiva que dañó el pensamiento, la literatura, el teatro y otras manifestaciones intelectuales y artísticas", como indicara Mario Coyula ("El trinquenio amargo" 361), estuvo marcado por la búsqueda de nuevas arquitecturas, apropiadas a las circunstancias del país: un estado poscolonial del Tercer Mundo. El conjunto, compuesto por cinco escuelas y diseñado por tres arquitectos ${ }^{1}$, fue declarado Monumento Nacional en febrero de 2013 (Juventud Rebelde 2013), poniendo fin a una polémica sobre su valor que se extendió por cinco décadas, en las que fue:

(...) satanizado/demonizado; sus autores, etiquetados como "intelectualoides" elitistas, y su influencia, considerada perniciosa para un joven estudiante de Arquitectura. Esta obra, la más publicitada del período revolucionario, fue crucificada precisamente por cumplir lo que se les había pedido inicialmente a sus arquitectos: hacer las escuelas de arte más hermosas de América Latina. Sus oponentes, afiliados a un pragmatismo tecnocrático, estaban dispuestos a sacrificar la belleza para lograr construcciones técnicamente impecables y en la gran cantidad que requería el país (Coyula, "El trinquenio amargo" 363).

A pesar de estar construidas con tecnologías tradicionales, las cinco escuelas muestran estéticas innovadoras que dotan a la arquitectura de significados radicalmente nuevos desde un punto de vista semiótico, cultural y social; pero la Escuela de Artes Plásticas destaca de modo particular: en ella Ricardo Porro continúa una búsqueda estética que inició con sus obras de la década de 1950, en oposición al racionalismo dominante, y que marcará su posterior trabajo en el exilio; una experimentación marcada por el barroquismo, el simbolismo y la analogía biomórfica. En Artes Plásticas, el autor presenta una vindicación de la tradición afrocubana mediante una organización de los espacios que rememora las aldeas africanas, pero al mismo tiempo rinde tributo a la mujer a través del uso de analogías antropomórficas. El valor estético de este planteamiento ha sido muy debatido; sin embargo, el abordaje de la ética que en él subyace no parece agotado: a la luz de nuevas miradas, su valor se multiplica.

El presente trabajo valorará la Escuela de Artes Plásticas de Ricardo Porro desde una perspectiva decolonial, un enfoque que ha ido permeando los análisis de las ciencias

1 El arquitecto cubano Ricardo Porro diseñó las escuelas de Artes Plásticas y de Danza Moderna; el arquitecto italiano Vittorio Garatti, las de Música y de Ballet; y el también arquitecto italiano Roberto Gottardi la de Artes Escénicas. 
sociales, las humanidades y la crítica de arte, pero no de la arquitectura. De este modo, se contribuirá no solo al conocimiento de la obra sino también a la crítica arquitectónica en tanto disciplina. El argumento a defender es el siguiente: la vindicación de la tradición afrocubana que soporta la conceptualización de la Escuela de Artes Plásticas es mucho más que un hecho anecdótico y puntual; representa un ejercicio de justicia cultural en el que pueden encontrarse destellos de descolonización arquitectónica, porque cuestiona la hegemonía del patrimonio arquitectónico moderno y "blanco" en Cuba. Como dicha hegemonía todavía persiste, el planteamiento de su arquitecto mantiene total actualidad. Para sostenerlo, se desarrollará un análisis hermenéutico que contempla tres etapas: (1) explicación de la novedad y validez de la perspectiva decolonial como marco teórico para analizar la producción arquitectónica; (2) presentación del marco histórico en que diseñan y comienzan a construir las ENA, en relación con los programas constructivos del momento y el trabajo precedente de Ricardo Porro y (3) valoración de la obra desde una perspectiva decolonial.

\section{La perspectiva de la modernidad/colonialidad, marco teórico para analizar la arquitectura}

\section{Algunos apuntes históricos y conceptuales sobre la colonialidad}

Conviene iniciar el análisis aclarando que se hablará indistintamente de "perspectiva de la modernidad/colonialidad", "crítica decolonial" o "perspectiva decolonial", porque no existe un consenso sobre cómo nombrar esta línea de pensamiento crítico que toma fuerza en las Américas y en otras partes del mundo. Por ejemplo, si bien Arturo Escobar (2003) hace un intento generalizador y se refiere al "programa de investigación de modernidad/colonialidad latinoamericano", y luego Santiago Castro-Gómez y Ramón Grosfoguel ("Prólogo") hablan de "teoría crítica decolonial” (33), siguiendo el concepto "giro decolonial" propuesto antes por Nelson Maldonado-Torres (Against War), puede verse en momentos más recientes que Eduardo Restrepo y Axel Rojas (2010) nombran esta línea como "inflexión decolonial". Conviene aclarar también que no existe acuerdo sobre "(des)colonial", "descolonial" o "decolonial", términos que Catherine Walsh (24) diferencia, pero solo los dos últimos se han ido generalizando. Como suele ocurrir en la historiografía de las ideas, es probable que se requiera más tiempo para asumir una convención al respecto, aunque quizás no se necesite porque, a pesar de todo, está claro que las distintas denominaciones refieren al mismo fin: desvelar el lado oscuro de la modernidad, la colonialidad. Por último, vale la pena anticipar que además existe gran confusión cuando se habla de esta interpretación de la modernidad y de su genealogía. En esa dirección, son esclarecedores los citados textos de Castro-Gómez y Grosfoguel ("Prólogo") y de Restrepo y Rojas (Inflexión decolonial), al hacer una historia de los sucesos académicos que dieron lugar a la 
concreción y expansión de la perspectiva. Ambos resaltan el carácter fundacional de los análisis de Aníbal Quijano. Igual apreciación ofrece el texto de Yasser Farrés y Alberto Matarán, que resume:

\begin{abstract}
La perspectiva de la modernidad/colonialidad o "crítica decolonial" se ha ido conformando a partir de los señalamientos que hizo el sociólogo peruano Aníbal Quijano (1991), desde la noción “colonialidad del poder", a la "teoría del sistema-mundo moderno" propuesta antes por el sociólogo estadounidense Immanuel Wallerstein $(1974,1979)$. Se trata de un enfoque que pone de relieve el rol fundamental de la expansión colonial hispánica en la conformación epistémica de la modernidad y desvela el eurocentrismo del proyecto civilizatorio globalizado. Esta propuesta quedó formalmente validada cuando ambos autores unieron sus puntos de vista (Quijano \& Wallerstein, 1992). De hecho, el propio Wallerstein $(1997 ; 2006)$ ha continuado desarrollándola ("Hacia una teoría” 334).
\end{abstract}

Sobre los aportes de Quijano al concepto "colonialidad", Grosfoguel ha aclarado, en una entrevista concedida a Luis Martínez Andrade ("Hay que tomarse"), que las feministas chicanas empleaban esa palabra antes que Quijano, y que la idea también estaba presente en las formulaciones de los pensamientos africano y negro de las Américas, aunque usaran otros términos ${ }^{2}$. La novedad introducida por Quijano sería que, al usar la idea "colonialidad del poder", ofrece una nueva forma de nombrar la articulación entre la noción "raza" y otras relaciones de poder, ayudando así a entender y distinguir "colonialismo" de "colonialidad" (Martínez Andrade 43-4).

En efecto, Quijano distingue "colonialismo" y “colonialidad”. Al primero lo define como una relación política y económica en la que la soberanía de una nación o pueblo descansa en el poder de otra nación, lo que convierte a esta última en imperio; y al segundo, como el conjunto de patrones de poder de larga duración que emergieron con el colonialismo pero definen la cultura, las relaciones intersubjetivas, la distribución del trabajo y la producción de conocimientos más allá de los estrictos límites de las administraciones coloniales. Acerca de tal distinción, Nelson Maldonado-Torres ha agregado que la colonialidad se mantiene tan viva en los libros, en los criterios para el desempeño académico, en los patrones culturales, el sentido común, la autorrepresentación de las personas, las aspiraciones del "yo" y tantos otros aspectos de la experiencia moderna que, como sujetos modernos, "respiramos colonialidad todo el tiempo y cada día" ("On the coloniality” 243). Por su parte, Castro-Gómez (2007) especifica que la colonialidad se articula por una estructura triangular entre "la colonialidad del ser", "la colonialidad del poder" y la "la colonialidad del saber" (79-80). Esas tres aristas operan de un modo indisoluble, por lo que urge descolonizar el poder, el saber

2 Para Mignolo (2013), las bases históricas de la decolonialidad se encuentran en la Conferencia de Bandung de 1955 que reunió a 29 países de Asia y África; “en el mismo momento en que la división en tres mundos se desmoronaba y se celebraba el fin de la historia y de un nuevo orden mundial" (8-9). 
y el ser al mismo tiempo; esto es, romper la hegemonía impuesta desde la supuesta universalidad de la racionalidad del sujeto moderno, que en realidad responde a un sujeto específico y local: el hombre blanco, capitalista, militar, patriarcal, heterosexual y de tradición judeocristiana que describe Grosfoguel ("La descolonización"). Dicho de otro modo: frente a la lógica de la modernidad/colonialidad aparece el horizonte epistémico de la transmodernidad/decolonialidad.

Los conceptos de decolonialidad y de transmodernidad -aparecieron en este orden dentro de las reflexiones colectivas en la red de pensamiento decolonial- destacan como categorías centrales de la propuesta filosófica decolonial, pero articulan otras nociones como "pensamiento fronterizo", "pluriversalismo" o "diversalidad". Sobre tales relaciones, resume Grosfoguel:

La transmodernidad es el proyecto utópico del filósofo de la liberación latinoamericano Enrique Dussel para trascender la versión eurocéntrica de la modernidad (Dussel 2001). En oposición al proyecto de Habermas de que lo que necesita hacerse es completar el proyecto incompleto de la modernidad, la transmodernidad de Dussel es el camino para completar el proyecto de descolonización inconcluso e incompleto en el siglo xx. En lugar de una sola modernidad centrada en Europa e impuesta como un diseño global al resto del mundo, Dussel aboga por una multiplicidad de respuestas críticas descoloniales a la modernidad eurocentrada desde las culturas subalternas y el lugar epistémico de los pueblos colonizados en todo el mundo. En la interpretación que Walter Mignolo hace de Dussel, la transmodernidad sería equivalente a la «diversalidad como proyecto universal», lo cual es resultado de un «pensamiento fronterizo crítico» como una intervención epistémica desde los subalternos diversos (Mignolo, 2000). Las epistemologías subalternas podrían proporcionar, siguiendo la redefinición que hace Walter Mignolo (2000) del concepto del pensador caribeño Edward Glissant, una «diversalidad» de respuestas a los problemas de la modernidad que conduce a la transmodernidad ("La descolonización de la economía política” 40).

\section{La colonialidad en la práctica profesional de arquitectura}

La hegemonía epistémica occidental se refleja también en la reproducción que tiene lugar en el "sur global" de los modelos urbanos y territoriales promovidos desde el "norte global". De ahí el sentido del concepto "colonialidad territorial” formulado por Farrés y Matarán (“Colonialidad territorial”), que alude al "conjunto de patrones de poder que sirven en la praxis territorial para establecer hegemónicamente una concep-

3 De hecho, incluyen otras ideas producidas fuera del contexto latinoamericano, como la de "pensamiento heterárquico", definida por el sociólogo griego Kyriakos Kontopoulos. 
FIGURA 1

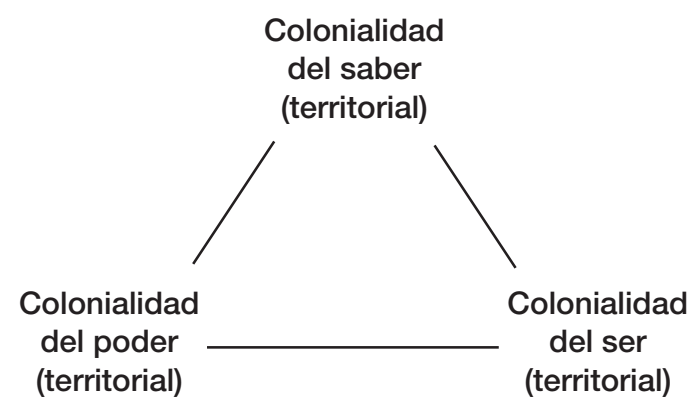

El triángulo de la colonialidad territorial. Manifestación particular de la estructura de colonialidad descrita por CastroGómez ("Decolonizar la universidad" 79). Fuente: Farrés y Matarán (“Colonialidad territorial").

ción del territorio sobre otras, que resultan 'inferiorizadas"' (152). Dichos patrones se sustentan en una estructura triangular (fig. 1) entre la "colonialidad del ser territorial" (hegemonía del "ser-urbano" sobre el resto de las formas de existencia humana nourbanas), la "colonialidad del saber territorial" (prácticas profesionales en que ciertos saberes dominan hegemónicamente las decisiones sobre cómo concebir y habitar el territorio, la ciudad y la arquitectura) y la "colonialidad del poder territorial" (ámbito de la intersubjetividad en que cierto grupo de gente define qué es territorialmente correcto y, por lo tanto, ostenta el poder de enunciación) (152-3).

Si se consideran la arquitectura, la ciudad y el territorio como manifestaciones, a distintas escalas, de una categoría de mayor generalidad (el ambiente construido), puede entonces procederse de forma análoga a Farrés y Matarán (“Colonialidad territorial"), y definir "colonialidad arquitectónica" como la hegemonía de una concepción de arquitectura sobre otras, que se articula a partir de la "colonialidad del saber arquitectónico", la "colonialidad del poder arquitectónico" y la "colonialidad del ser arquitectónico". Lo mismo, en términos urbanos. La relación de la colonialidad en las distintas escalas de trabajo podría explicarse con el esquema de la fig. 2.

Por razones de espacio, es imposible agotar aquí las tres aristas de la colonialidad en la escala arquitectónica (escala a la que pertenece la obra en estudio); por ello, interesa explorar una en específico: la colonialidad del saber arquitectónico. Al respecto, aceptando la división del saber arquitectónico en dos grupos, "saber práctico" y "saber teórico", aunque estos no estén totalmente desvinculados (cf. Farrés y Michel 61-3), podría afirmarse que existen dos grandes grupos de jerarquías: 1) en cuanto al "saber producir objetos arquitectónicos" (el saber práctico); y 2) en cuanto al "saber valorar objetos arquitectónicos” (saber teórico). En el primer grupo están las jerarquías relativas al "saber representar", "saber proyectar", "saber construir", "saber pensar" y "saber aprender" que menciona el arquitecto y profesor colombiano Alberto Saldarriaga; y en el segundo, la jerarquía que atañe al "saber ver" que defendiera Bruno Zevi, o dicho de otro modo, el "saber apreciar", que involucra al "saber estético" (o simplemente la estética). 
FIGURA 2

Colonialidad

del saber territorial

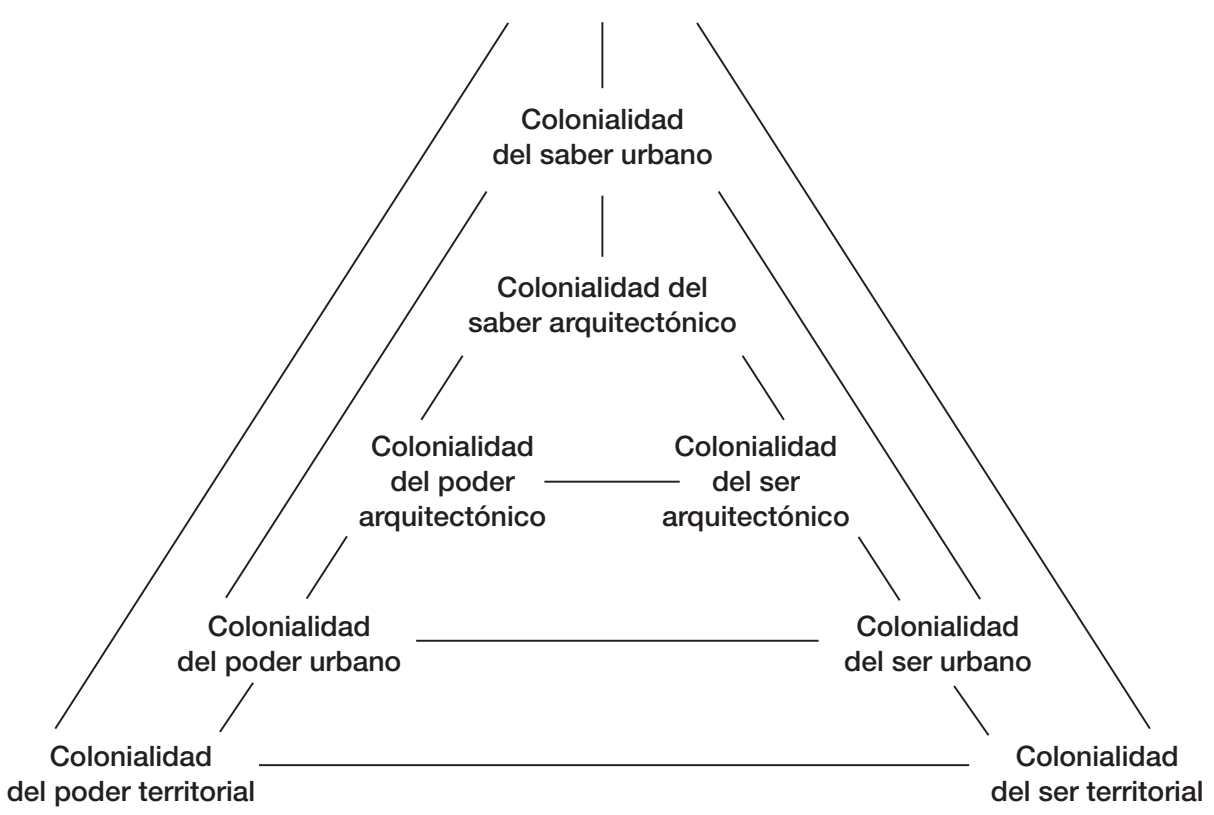

Aproximación a la estructura de la colonialidad territorial/urbano/arquitectónica. Elaboración propia.

En cuanto a la colonialidad del saber arquitectónico, interesa prestar atención a una manifestación particular que se relaciona directamente con la ética: la cuestión estética. En esa dirección, vale la pena recordar que, como describe Grosfoguel ("Izquierdas e Izquierdas Otras"), en el sistema mundo moderno/colonial ha existido una "jerarquía estética global donde se privilegian las formas de belleza y gustos occidentales y se inferiorizan las formas de belleza y gustos no-occidentales" (14); y que, como señala Joaquín Barriendos, ha existido una "colonialidad del ver" en los regímenes de la visualidad impuestos por Occidente. Tomando en cuenta ambas ideas y el hecho que la arquitectura es un componente particular dentro del sistema de las artes visuales (aunque no se agote en la noción de arte), puede afirmarse que también ha existido una "colonialidad del ver arquitectónico"4 impuesta por la modernidad arquitectónica, pues niega todas las tradiciones precedentes. Si se desea una fecha representativa de la consolidación de la colonialidad del ver arquitectónico moderna, podría ser 1908, cuando Adolf Loos "criminalizó" el uso del ornamento en su

4 Barriendo considera que "la colonialidad del ver, como la colonialidad del poder, del ser y del saber, es también constitutiva de la modernidad" (15). En el presente trabajo, en cambio, consideramos que es constitutiva, pero que el ver no debe considerarse al margen del ser, el saber y el poder, sino que constituye una forma específica de saber. 
ensayo Ornament and crime. Tendrán que pasar varias décadas para que comience a cuestionarse la autoproclamada universalidad de la modernidad arquitectónica. El cuestionamiento provendrá de las periferias del sistema-mundo, especialmente de parte de ciertos arquitectos latinoamericanos que dieron origen a lo que Kenneth Frampton llama "regionalismo crítico" (318-32).

$\mathrm{Si}$, en términos filosóficos, la modernidad es un proyecto universalista e imperial eurocéntrico que niega la validez de toda experiencia no-occidental, o la subordina a sus intereses creando "líneas abismales" (cf. Santos 31-8) entre "la mismidad" y "la otredad", de modo que esta última no tiene posibilidad de existencia; la arquitectura moderna, por su parte, es el reflejo material de esa lógica. No se olvide que, como expone Josep María Montaner, los arquitectos modernos más influyentes hicieron una conveniente apropiación del concepto historicista del Zeitgeist -el espíritu (Geist) del tiempo (Zeit) - para justificar "una afirmación antihistórica hecha en falso: construir una propia genealogía moderna a costa de negar los precedentes históricos y apropiarse del sentido de la historia negándolo al mismo tiempo" (35). Los promotores del movimiento moderno respaldaron esa afirmación mediante un andamiaje historiográfico que redujo la historia de la arquitectura a las grandes obras y equiparó el papel del movimiento moderno con la importancia histórica y el esplendor de aquellas. Así, se justificó "la actuación de los arquitectos vanguardistas y presentándoles, espléndidamente aislados de todo precedente, como si fueran unos héroes míticos que se enfrentaban al enemigo de la decadencia academicista", y se legitimó también "los valores de un nueva moralidad con efectos pedagógicos, regeneradores e higienistas” (Montaner 35). Esa actitud moderna condujo a un distanciamiento de la arquitectura respecto de las realidades culturales preexistentes (costumbres, saberes, tecnologías, concepciones estéticas y espaciales, etcétera), que continuará reproduciéndose en la posmodernidad, período en que los arquitectos -y las pocas arquitectas- del star system global siguen imponiendo "arquitecturas de autor" que son muy independientes de los contextos locales. De este modo, la arquitectura y el urbanismo posmodernos confirman la afirmación decolonial de que la globalización es una radicalización de la modernidad.

En el caso de la modernidad arquitectónica latinoamericana (décadas de 1950, 1960 y 1970 aprox.), existirá un intento por reterritorializar los modelos modernos europeos, pero la búsqueda no pasará de ser una crítica eurocéntrica al eurocentrismo de la arquitectura moderna. En efecto, aun cuando las propuestas se insertan en los discursos nacionalistas que reinterpretan los modelos arquitectónicos y urbanos coloniales que respondieron a la lógica imperial/occidental, no contemplan una valoración de las posibilidades, en términos estéticos o en el uso del espacio, que podrían ofrecer las tradiciones originarias o las tradiciones de origen africano ${ }^{5}$. La modernidad latinoamericana continúa la actitud del eclecticismo burgués y blanco de décadas anteriores.

5 No por casualidad se habla del «modelo europeo de ciudad en América Latina» (cf. Segre y Vélez 2000). 


\section{Marcos histórico y arquitectónico en que tienen lugar las ENA}

\section{La arquitectura escolar en los primeros años de la Revolución Cubana}

El arquitecto cubano Heriberto Duverger (1988), parafraseando una definición de Shakespeare sobre el teatro, describe la arquitectura escolar de los primeros años de la Revolución Cubana como "el espejo en el que se refleja el desarrollo del sentimiento estético de una época” (26). Su descripción no podría ser más acertada: la arquitectura escolar es el contenedor por excelencia de la utopía central del proceso revolucionario, la creación del "hombre nuevo" y, por ello, está cargada de contenidos que se prestan a múltiples lecturas políticas y sociológicas. El autor también acierta al afirmar que "los planteamientos más álgidos de la arquitectura cubana fueron desarrollados a través de la construcción escolar" (25), pues el devenir de aquel programa refleja las grandes contradicciones del proceso revolucionario, definidas no solo por tratarse de "un estado socialista surto en e1 mar de las Antillas a la entrada del Golfo de México y a noventa millas de la mayor agresividad que puede desarrollar un enemigo poderoso" (26), como insiste el autor. Esas contradicciones se deben también -y quizás, sobre todo- a que el al ambicioso proyecto socioterritorial proclamado por el estado cubano nunca tuvo un sustento económico sólido, que se basara en el desarrollo real de las capacidades económico-productivas del país: dependió en todo momento de las prebendas que ofrecía la Unión Soviética (URSs), lo que se evidenció desde fechas muy tempranas. De hecho, si bien entre 1959 y 1989 el estado cubano construyó un sinnúmero de instalaciones educativas (tabla 1) y realizó enormes inversiones en otros programas, esa transformación del ambiente urbano fue posible por la participación de Cuba dentro de las políticas de "vitrinas simbólicas" (cf. Grosfoguel, "Cambios conceptuales") que la URSS y EEUU establecieron como estrategias de hegemonía global en medio de la Guerra Fría. Muy recientemente ha quedado claro: si enormes fueron los flujos de capital y recursos que llegaron al país desde el bloque soviético, también lo fue la deuda (que todavía se mantiene) ${ }^{6}$.

La problemática descrita marca el origen, largo proceso constructivo y situación posterior de las ENA (1961-1964), que junto con esa suerte de alter ego suyo que es la Ciudad Universitaria José Antonio Echeverría, CUJAE (1961-1969), evidencian tanto el fértil campo de experimentación que representó el programa constructivo educacional durante la primera década de la Revolución como las dificultades económicas y burocráticas que debían sortearse para desarrollar búsquedas arquitectónicas distantes del dogmatismo de Estado que pronto se impuso. Tanto las ENA, explorando al máximo

6 Tras la caída de la uRss el gobierno ruso reclamó el derecho a cobrar la deuda. En julio de 2014, la Duma (parlamento ruso) decidió condonar el 90\%. Véase, por ejemplo, "La jugada de Putin de perdonar la deuda de Cuba", publicado por ввС el 11 de julio de ese año. Consultado en: http://www.bbc.co.uk/mundo/noticias/2014/07/140711_rusia_cuba_visita_deuda_tsb 
TABLA 1

\begin{tabular}{|l|c|c|}
\hline \multirow{2}{*}{ Variable } & \multicolumn{2}{|c|}{ Años } \\
\cline { 2 - 3 } & $\mathbf{1 9 5 9}$ & $\mathbf{1 9 8 9}$ \\
\hline Población (millones de habitantes) & 6.0 & 10.0 \\
\hline Centros de educación primaria (u) & 7679 & 13.034 \\
\hline Centros de educación secundaria (u) & 81 & 2149 \\
\hline Sedes universitarias (u) & 3 & 35 \\
\hline
\end{tabular}

Instalaciones educativas producidas por el gobierno cubano entre 1059 y 1989. Fuente: Elaboración propia basada en Segre (Arquitectura antillana).

las posibilidades creativas de una tecnología artesanal basada en la arcilla (ladrillo, losas de cerámica, etc.), como la CUJAE, en su búsqueda homóloga con tecnologías más industrializadas (hormigón y acero), se vieron lastradas por "el maniqueísmo dogmático que borra sistemáticamente las diferencias y sofoca la individualidad" (Coyula, "El trinquenio amargo" 362), responsable en última instancia de la estandarización generalizada en las instituciones escolares a partir de los años setenta. De estas, solo destacarán algunos casos excepcionales ${ }^{7}$.

Para comprender las particularidades que afectan al proceso de diseño y construcción de las ENA debe considerarse que tienen lugar en un complejo contexto sociopolítico y económico, definido por el inicio del bloqueo comercial, económico y financiero de EEUU hacia Cuba (1960) que afectará a las políticas estatales en relación con los modelos arquitectónicos a promover ${ }^{8}$. Como indicara Segre (Arquitectura antillana), condicionada por dichas circunstancias económicas, la arquitectura de los años sesenta responderá a tres tendencias arquitectónicas cuyos límites "no resultan nítidos": (1) la continuidad de las tipologías tradicionales, (2) el trinomio integralidad-creatividad-sensibilidad social y (3) el expresionismo figurativo. Sobre las obras y autores representativos del momento, el autor señala:

En cada una de ellas existen inflexiones y alternativas identificadas con la personalidad de los creadores. La primera corresponde al grupo de profesionales que llevan

7 Duverger precisamente muestra esos casos excepcionales - como la Escuela Vocacional “V. I. Lenin” en La Habana y su homóloga "Máximo Gómez" en Camagüey- que lograron explotar cierta flexibilidad del sistema constructivo "Girón" (con el que se construyeron desde círculos infantiles hasta centros universitarios), al tiempo que se personalizaron los espacios por medio de la gráfica o el diseño ambiental. La estandarización homogeneizadora también ocurrió en el resto de los programas arquitectónicos sociales (viviendas, hospitales, etc.)

8 Sobre el tema, véase los textos de Eliana Cárdenas: "En el cambio de milenio: polémicas y realidades en la arquitectura cubana". Archivos de Arquitectura Antillana 5.10 (2000): 128-133; Mario Coyula: "El trinquenio amargo y la ciudad distópica: autopsia de una utopía”. Cuba: contrapuntos de cultura, historia y sociedad. Ed. Francisco Scarano y Margarita Zamora. San Juan: Callejón, 2007. 361-385; y de Yesser Farrés y Roberto Segre: "Cinco decenios de teoría de la arquitectura en Cuba (1963-2013) y un diálogo intergeneracional: entrevista a Roberto Segre”. $A C E$ 8.23 (2013): 77-94. 
FIGURA 3
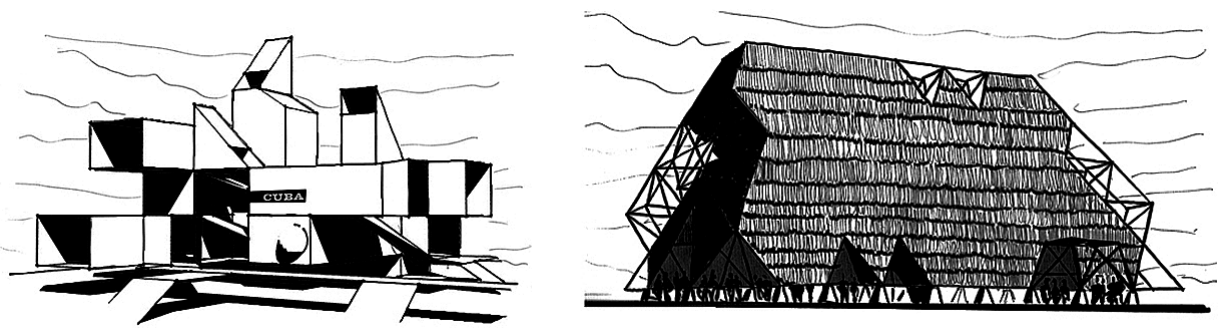

Izquierda: proyecto arquitectónico de Sergio Baroni, Vittorio Garatti y Hugo. Derecha: proyecto de Javier Gutiérrez

a cabo administrativamente las construcciones seriadas; en la segunda, Fernando Salinas se destaca por la búsqueda de la integralidad artística y la personalización de la masividad, Antonio Quintana (n. 1919) por el racionalismo estetizado con la naturaleza, y Juan Tosca (n. 1928) por la creatividad tecnológica; la tercera se identifica con el expresionismo escultórico de Ricardo Porro (n. 1925) y el naturalismo orgánico de Walter Betancourt (1932-1978) (Arquitectura antillana 361).

\section{Ricardo Porro: trayectoria y precedentes de la Escuela de Artes Plásticas}

Ricardo Porro (Camagüey, Cuba, 1925-París, Francia, 2014) se graduó de arquitecto por la Universidad de La Habana en 1949. Al año siguiente diseñó su primer proyecto, la Villa Armenteros, para un burgués muy adinerado, pero el propio autor prefiere olvidarlo:

Yo me las arreglé antes de graduarme para buscarme un cliente que me permitió hacerle una casa, mi primera obra: la casa Armenteros. Hoy preferiría que todo el mundo se olvidara de ella. Tenía la influencia que teníamos muchos de nosotros en aquella época: la de Mies Van der Rohe. Era una casa muy miesiana con algunos detalles un poco personales. Actualmente está muy alterada y francamente prefiero olvidarla. Después pude tener algunos pequeños clientes, pero hay que decir que en aquella época a los arquitectos jóvenes con cierto talento les daban pequeñas obras, pequeñas casitas. Los clientes que logré conseguir eran de pequeña y mediana burguesía, salvo Armenteros, que era alta burguesía (Porro cit. en Morales, "Ricardo Porro entrevisto" 14).

Ese mismo año viaja a Europa para continuar estudios. Vive en Francia hasta 1952 y acude al estudio de Le Corbusier, donde trabaja como su alumno durante poco tiempo:

9 En el concurso nacional para el pabellón de Cuba a la Exposición Universal de Montreal 1967 se vieron representadas las distintas tendencias arquitectónicas. El proyecto ganador fue el de Sergio Baroni, Vittorio Garatti y Hugo Dacosta, mientras que el de Javier Gutiérrez recibió una de las menciones. 
Yo quería trabajar con Le Corbusier, fui a verlo y me dijo: "Muy bien, trabaje conmigo", luego me preguntó cuánto tiempo me quería quedar, le dije que un año, él me respondió que un año no, que cinco o nada, y le contesté que aceptaba los cinco años; pero después empecé a ver lo que eran los alumnos, y que más o menos lo que hacían era copiar al maestro y hablaban y elaboraban croquis... Y mi espíritu de revuelta, de ser yo mismo, mi individualismo, me sacó de allí y decidí no volver más a su oficina y formarme por mí mismo; y mi preparación fue La Sorbona, el estudio de la filosofía, el estudio de las humanidades en general, que me interesaba mucho más que trabajar en una oficina de arquitecto donde iba a aprender a la manera del maestro. Prefería lo otro. Y Europa me formó una mentalidad (Porro cit. en Fernández 5).

En este período, Porro estudia en La Sorbona y en el Instituto de Urbanismo de París. También participa en los cursos del ciam en Venecia, Italia, donde recibe la influencia de Rogers, Gardella, Albini y Bruno Zevi (Morales, "Ricardo Porro entrevisto" 14) ${ }^{10}$. En París, conoce a Picasso, quien lo recibe con frecuencia:

yo era un chiquillo que le hacía preguntas idiotas, pero Picasso se las arreglaba para darme unas respuestas que yo entendiera. Fue el primero que me habló de símbolos y que me habló de la falta de símbolos de muchos arquitectos y artistas del siglo xx. Picasso se consideraba a sí mismo como un artista del símbolo, para mí eso fue una revelación, eso me abrió el mundo (Porro cit. en Fernández 8).

De regreso a Cuba, construye la citada Villa Armenteros, y luego diseña y construye una serie de residencias para clientes de la pequeña y mediana burguesía: la Villa Ennis (1953), la Villa San Miguel (1953), la Villa Villegas (1953), la Casa García (1954), la Casa Abad-Villegas (1954) y la Casa Timothy Ennis (1957), reconocidas hoy dentro de las obras más importantes del movimiento moderno en Cuba (Morales, "Fallece en París").

Sin embargo, la década del cincuenta es un período convulso: el 10 de marzo de 1952, Fulgencio Batista perpetra un golpe de Estado que le permite gobernar de facto hasta 1954; luego, a pesar de ser derrotado en las elecciones presidenciales, continúa en el poder hasta 1958, situación que solo terminará el 1 enero de 1959, con el triunfo revolucionario encabezado por Fidel Castro. En ese contexto, conspirará contra el dictador una parte de la juventud universitaria, entre los que se cuentan, de modo especial, ciertos grupos de la Facultad de Arquitectura ${ }^{11}$. Porro también se implica y debe exiliarse en Venezuela, donde recibirá el apoyo del arquitecto José Raúl Villanueva

10 Debe hacer referencia a Ernesto N. Rogers, Ignazio Gardella, Franco Albini y Bruno Zevi, importantes arquitectos y teóricos italianos ligados a los ciam. (Nota de A.)

11 El 13 de marzo de 1957, José Antonio Echeverría, líder nacional de la Federación Estudiantil Universitaria y estudiante de Arquitectura, comanda al grupo que intentará ejecutar a Batista asaltando el Palacio Presidencial. 
para ingresar al claustro de profesores de la Facultad de Arquitectura y Urbanismo de la Universidad de Caracas. En aquella institución encuentra un espacio apropiado para desarrollarse (Morales, "Ricardo Porro entrevisto" 14-5). En Caracas coincidirá con el pintor cubano Wilfredo Lam -quien realizara en 1957 uno de los murales de la Ciudad Universitaria- y conocerá a Vittorio Garatti y Roberto Gottardi (Morales, "Fallece en París"). Permanece en la ciudad hasta agosto de 1960, año en que regresa a Cuba para trabajar en planificación urbana (Pizarro 26). Es entonces cuando recibe la invitación de la arquitecta Selma Díaz para actuar como coordinador general del proyecto de las Escuelas Nacionales de Arte, que debe construirse en terrenos del barrio de Cubacán, ubicado en las afueras de La Habana. Porro extiende su invitación a Garatti y Gottardi. Entre 1961 y 1965, trabaja en el diseño y construcción de las escuelas de Artes Plásticas y Danza Moderna, hasta que se ve forzado a emigrar a Francia en 1966 (Morales, "Fallece en París").

\section{La Escuelas Nacionales de Arte}

El conjunto de las Escuelas Nacionales de Arte se ubica en los terrenos de golf del entonces Havana Country Club, en la zona oeste de La Habana. Fidel Castro propuso hacer allí "los edificios más nuevos y bellos que se pudieran construir en el mundo" (Morales, "Ricardo Porro entrevisto" 16). Para el momento de su diseño, se había instalado el bloqueo económico de Estados Unidos a Cuba (abril de 1961), con la consecuente escasez de ciertos materiales de construcción, especialmente el acero y el cemento, por lo que se pidió a los arquitectos que no usaran "acero ni hormigón, sino materiales y mano de obra artesanales" (Martín 46). Por esta razón se decide emplear la arcilla como principal material y la bóveda tabicada como técnica constructiva, dos puntos que, sumados al principio de integración al paisaje, darán unidad al conjunto arquitectónico. La capacidad creativa de los arquitectos concretará una nueva expresividad de la bóveda tabicada (Pizarro y Rueda 2013). En 1964, cuando los arquitectos comenzaban a ser cuestionados y sus obras paralizadas, el arquitecto, artista y crítico cubano Hugo Consuegra comentaba:

El forastero que visita las escuelas de arte, independientemente de que le gusten o no -y lo más frecuente ha sido que se entusiasme con ellas- recibe una sensación de exceso y grandilocuencia, y ello naturalmente se presta a críticas, sobre todo entre aquellos arquitectos formados en los postulados de una arquitectura más directa y menos espectacular. También aquí cabe preguntarse: ¿no es grandilocuente y espectacular nuestro momento histórico?

[...]

Si la cultura cubana -en cualquiera de sus manifestaciones- aspira a reflejar la revolución, estimo que debe hacerlo con plena conciencia de cierta desorbitación; quiero decir: voluntariamente indiscreta y tremendista (15). 
En defensa de las obras, Consuegra identificaba tres coincidencias conceptuales "que resultan altamente interesantes para el crítico" y que "no han sido formuladas nunca por sus autores, pero [...] provienen de una tremenda realidad exterior a ellos". La primera está relacionada con el carácter de los arquitectos, y sería la escisión entre el creador y su medio:

Los arquitectos de estas obras, no importa que sean cubanos o extranjeros, son, por su formación y sus proyecciones, verdaderos "aristócratas" de la cultura: arquitectos humanistas, productos de todo el complejo cultural contemporáneo. Bien entendido que estos "aristócratas" son fieles a la revolución, marchan hombro a hombro con el pueblo al corte de caña y montan guardia fusil en mano, pero en tanto arquitectos, son unos solitarios. Su obra es pues, comprendida a medias; saboreada sólo por sus iguales; delicias de los entendidos sus detalles; arte de exquisitez espacial, que ni siquiera es totalmente valorado por todos los arquitectos, sino por los "arquitectos exquisitos". Frente a este arte, el hombre medio reacciona favorablemente halagado, "encantado" vale decir, pero sin dominio real de su criterio, impresionado tan sólo por el espectáculo. Esta desproporción entre la calidad de la obra -que por supuesto, no es solamente espectáculo- y la capacidad normal de evaluarla, está presente en todo el arte contemporáneo, siendo válida la ecuación inclusive para los países de más alta cultura, pero en un país subdesarrollado como el nuestro, la grieta se hace verdaderamente dolorosa (15).

La segunda condición es la voluntad común de desintegrar la unidad espacial, presente en la estructura de pabellones aislados, "con su cubierta independiente en Artes Dramáticas, Ballet y Artes Plásticas, articulándose según ritmos asincopados -ritmos inesperados, es importante precisar, dándonos una visión aditiva, nunca total” (16). La tercera, la angustia espacial o hipertensión espacial, que se consigue con "la agudización extrema de los contrastes, las angularidades dinámicas o las superficies revolventes [...], la voluntad de permanecer en desequilibrio, [...] en perpetuo movimiento" (16). En opinión del autor, estas tres condiciones volvían a las escuelas manieristas, más que barrocas, que era el argumento de Porro $^{12}$.

\section{Conceptualización de la Escuela de Artes Plásticas}

Las escuelas de artes, reconoce Porro, fueron el salto mortal del arquitecto. Consciente de la oportunidad, hizo converger en ellas los contenidos de sus muchas

12 Escapa a este artículo agotar las particularidades de cada escuela, pero puede consultarse al respecto el libro del arquitecto e historiador estadounidense John A. Loomis: Revolution of Forms - Cuba's Forgotten Art Schools. Nueva York: Princeton Architectural Press, 1999. Sobre la idea del barroquismo en la obra de Ricardo Porro, véase Kaup, Monika. "«Vaya Papaya!»: Cuban baroque and visual culture in Alejo Carpentier, Ricardo Porro, and Ramón Alejandro". PMLA 124.1 (2009): 156-171. 
FIGURA 4

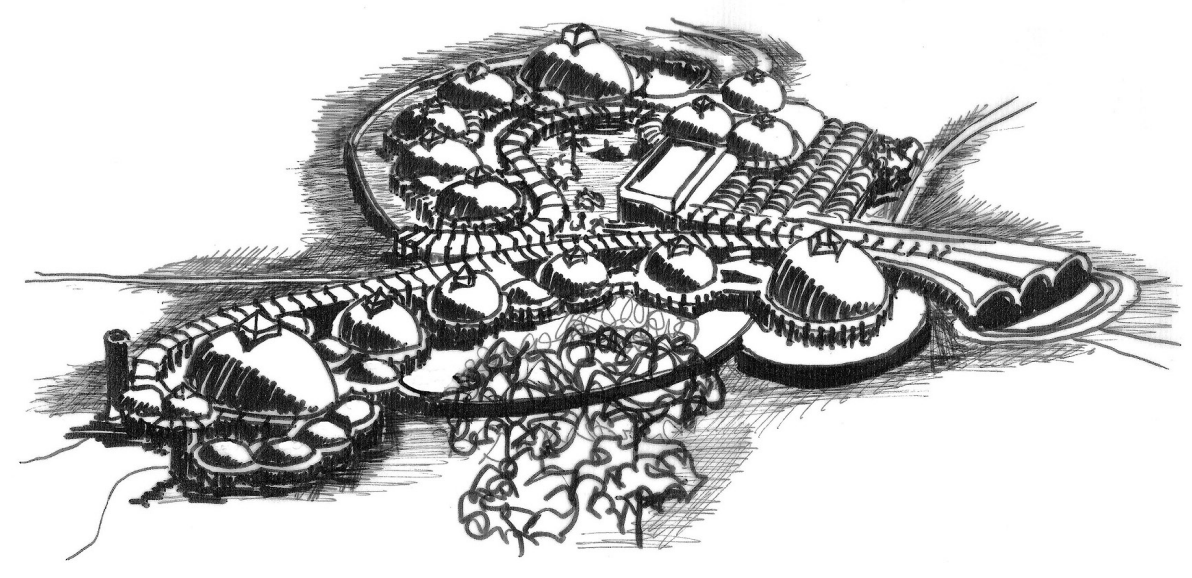

Sketch de la Escuela Nacional de Artes Plásticas del arquitecto Ricardo Porro. C Elaboración propia

influencias culturales. En una entrevista concedida a Juan Luis Morales, expone sobre Artes Plásticas (fig. 4):

Cuando empecé a analizar la Escuela de Artes Plásticas, en seguida pensé en la tradición, pero no quise enfocarla como lo hubiera hecho antes. Es decir, no era la arquitectura aristocrática la que me interesaba, sino cómo lograr darle una expresión a lo que nunca había tenido arquitectura, el lado negro de Cuba. Había una aristocracia católica, y un pueblo con una mezcla de religiones africanas en sincretismo con la católica, y eso es Cuba. Los que triunfaron fueron los africanos, más que los curas católicos; la aristocracia se fue y quedó el pueblo. Quise hacer una arquitectura que expresara eso. ¿Cómo hacerla? No existía ningún precedente. Existía una música y una danza sumamente sensuales y eróticas, y un sentido religioso detrás de todo eso. Estaba Lam, y ¿ cómo expresa el lado negro? Lam va a lo que es «la no-limitación del ser» en las civilizaciones mágicas (...) Es un mundo en el que un hombre puede ser tigre, serpiente, o puede convertirse en árbol; los límites del ser no están fijos. (...) Yo decidí referirme a otra imagen, a una imagen primera: la diosa de la fecundidad. Concibo un edificio como Eros, le doy senos. Es la imagen de la Diana de Éfeso, que siempre me impresionó, esa Diana con senos en todo el torso. Es el punto de partida de mi Escuela, puede ser Gea, la diosa griega de la fecundidad, y también puede ser Ochún. El contenido en general era el Eros y, desde luego, el Eros que heredamos de África (cit. en Morales 15).

La alegoría de la mujer está también en la planta arquitectónica del conjunto, con su distribución inspirada en el aparato reproductor femenino (fig. 5). Este se expresa 
FIGURA 5

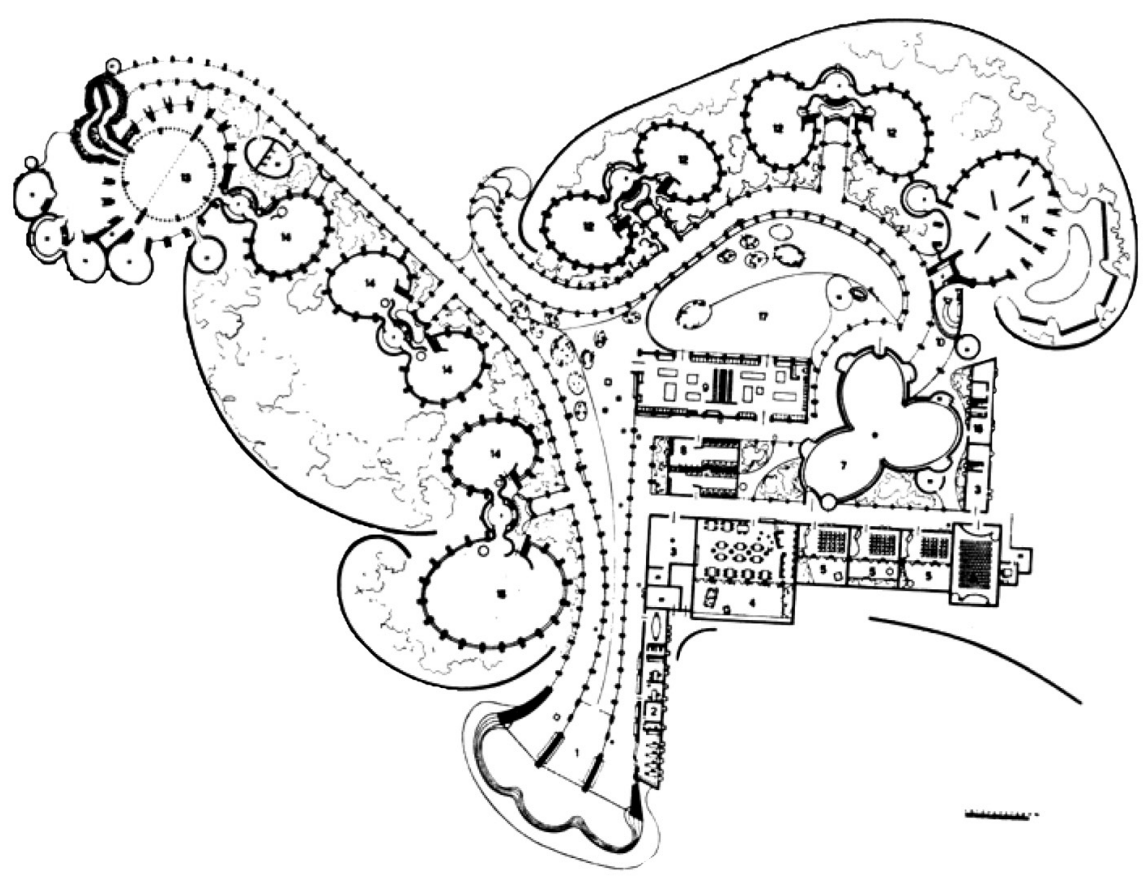

Planta arquitectónica de la Escuela de Artes Plásticas. Fuente: Consuegra.

sobre todo en la fuente del patio central: una papaya que emanaba un chorro de agua (fig. 6) que, como señala John A. Loomis (1999), fue clausurado por órdenes del partido comunista por considerarlo obsceno (123). Tómese en cuenta que en Cuba la papaya es conocida como "fruta bomba", nombre que proviene del término yoruba "embomba" y hace referencia a la vagina, como reseña Guillermo Cabrera Infante. Esta referencia sexual está ampliamente anclada en el imaginario popular. En ese sentido, si se considera que Wilfredo Lam fue el primero en explorar en la pintura el significado sexual de esta fruta (Cabrera 12), y se anota la estrecha relación entre Lam y Porro, es comprensible pensar que la decisión del arquitecto estuviera mediada tanto por la interpretación popular como por la influencia de su amigo pintor.

El otro componente de la conceptualización de esta escuela es la voluntad de que la arquitectura se haga ciudad, evidente en la centralidad de los espacios colectivos y las galerías porticadas, que rememoran la tradición colonial de La Habana -"La ciudad de las columnas", de la que poco después hablará Alejo Carpentier-, aunque al mismo tiempo quiere ser aldea (fig. 7). Como comentara Porro: “(Es) una imagen de ciudad y es aldea. Es una aldea, ya que lo único que hice fue una entrada, una calle estrecha y una plaza, pero es imagen de ciudad" (Porro en Morales, "Ricardo Porro entrevisto" 17). Ciudad y feminidad son las dos ideas centrales del recinto: 


\section{FIGURA 6}

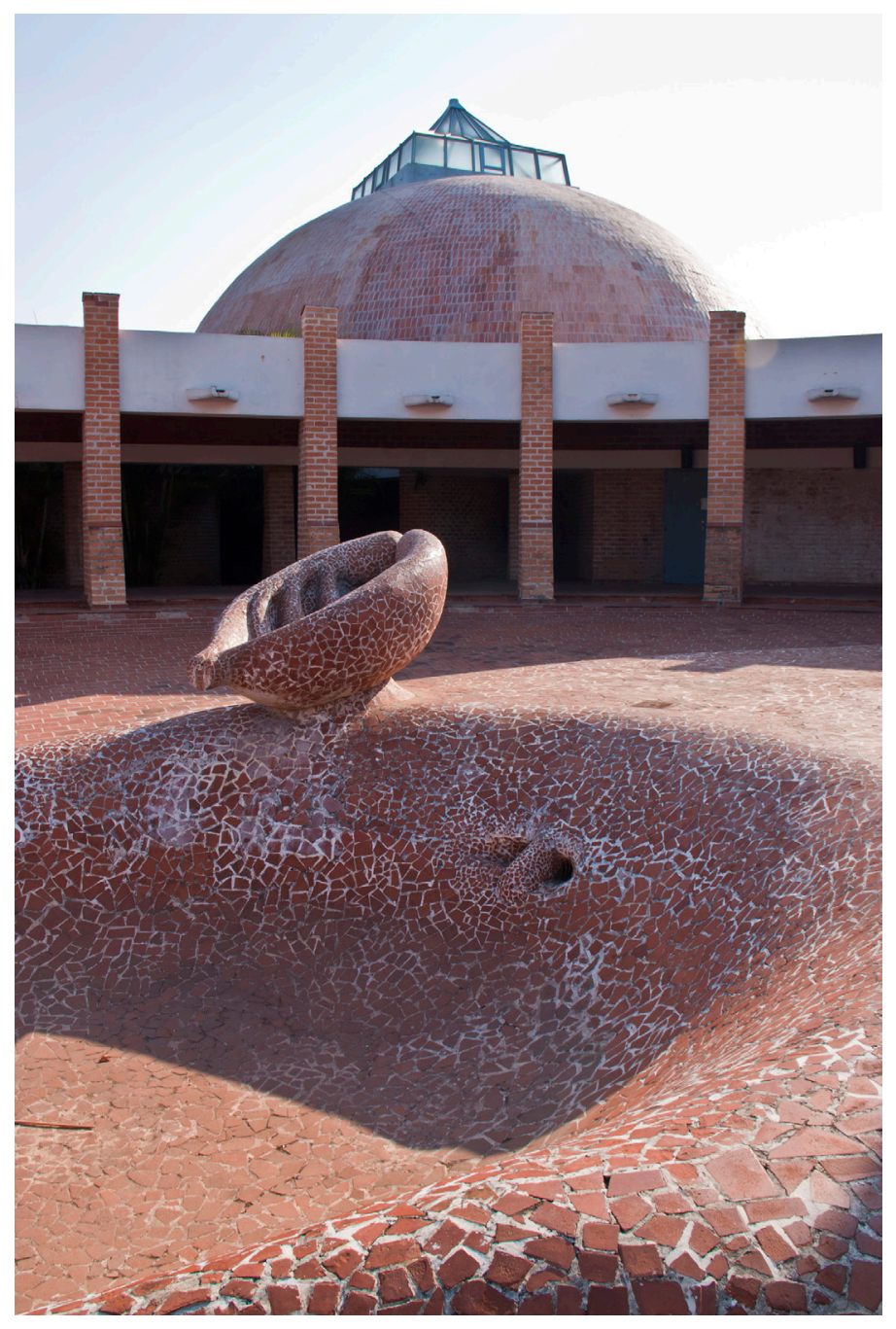

Escultura de la papaya, en la plaza central de la Escuela de Artes Plásticas. Foto: Cortesía de Arq. Libertad Rodríguez.

Yo traté de hacer un edificio que fuera feminidad, pero también (porque yo venía influenciado de lo que era el urbanismo de Venecia), que fuera ciudad, pero una ciudad que se convirtiera en Eros, una ciudad que fuera amor. Entonces ¿cómo la interpreté? Pues haciendo que todas sus aulas de clases, todos los distintos talleres fueran como teatro arena y a su vez el teatro arena me daba como un huevo o me daba un seno, huevo que es origen del mundo, origen de la vida y seno que también tiene que ver con lo iniciático: amamanta al que nace. Yo me daba cuenta de que haciendo esto, concebía de una forma pura y simple el eterno problema del hombre: el Eros (Porro cit. en Fernández 6). 


\section{FIGURA 7}

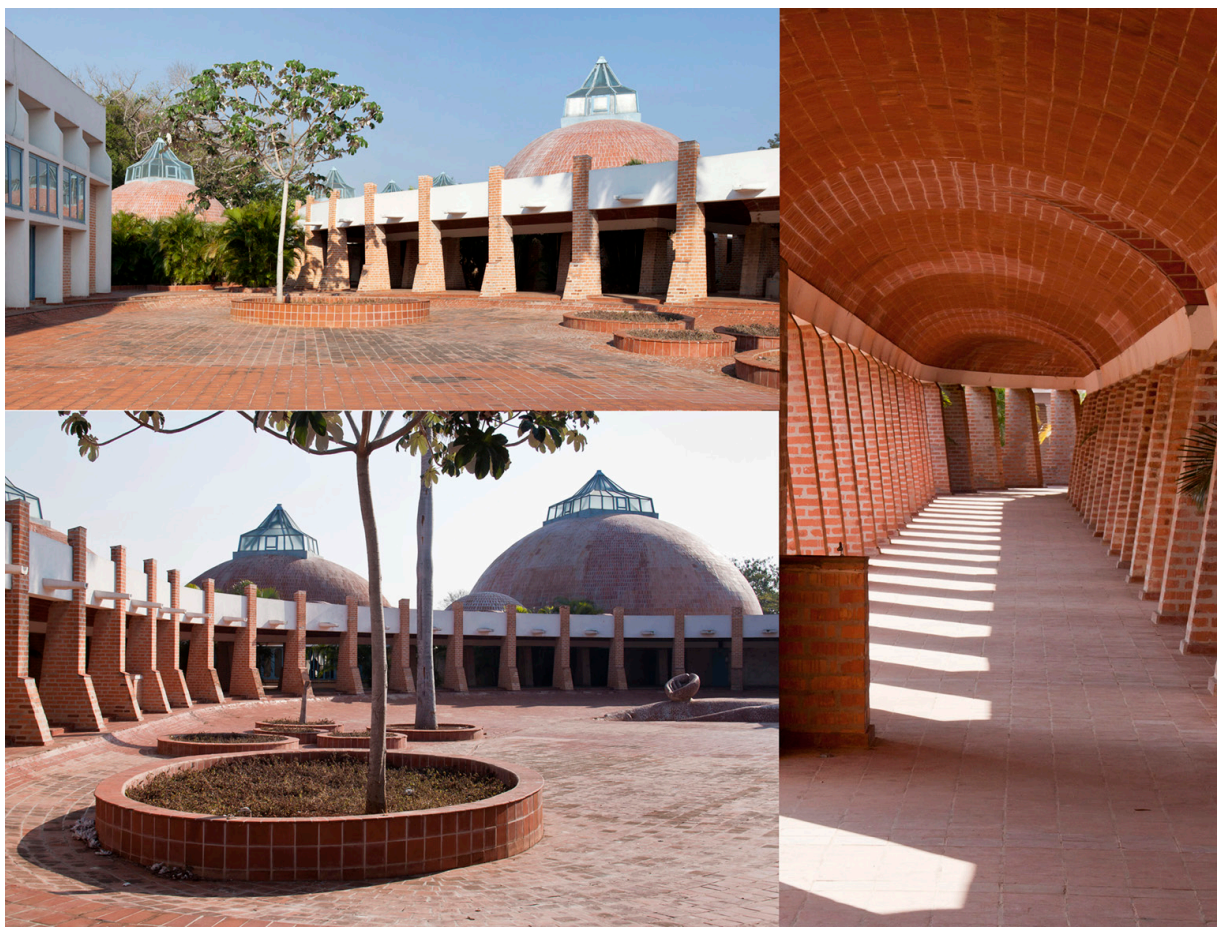

Vistas de la plaza central de la Escuela de Artes Plástica (izquierda arriba y abajo) y detalles de las galerías porticada (derecha). Fotos: Cortesía de Arq. Libertad Rodríguez.

\section{Para una mirada decolonial a la Escuela de Artes Plásticas}

\section{La modernidad arquitectónica como colonialidad: persistencia en la primera década de la Revolución Cubana}

Puede afirmarse que la modernidad arquitectónica cubana, que toma auge en la década de los cuarenta pero alcanza su máximo esplendor en los años cincuenta, venía reproduciendo la colonialidad arquitectónica impuesta por el eclecticismo burgués y blanco de décadas anteriores, es decir, en general reproducía las pretensiones de la arquitectura occidental. Esta tendencia continuó dominando en los inicio de los sesenta. A excepción del "expresionismo figurativo", caracterizado por el fuerte arraigo local que otorgan el empleo de materiales y tradiciones constructivas y la búsqueda conceptual en los imaginarios locales, las otras dos tendencias mencionadas por Segre, "la continuidad de las tipologías tradicionales" y "el trinomio integralidadcreatividad-sensibilidad social", continuaron inscritas en un "desarrollismo abstracto" que es consecuente con el "universalismo abstracto" de la filosofía de la modernidad 
(Arquitectura antillana $)^{13}$. Dicho desarrollismo/universalismo abstracto priorizará el uso de los materiales y técnicas constructivas novedosos ${ }^{14}$, así como ciertas estéticas funcionalistas que, si bien dejaron edificios de una calidad muy superior a los construidos desde los años setenta, también asentaron la creencia de que el desarrollismo y la industrialización son la única salida para responder a las demandas arquitectónicas y urbanas del Tercer Mundo. De esa forma, quedaría establecida cierta colonialidad del saber arquitectónico en detrimento de las propias tecnologías tradicionales no convencionales, pues si bien las primeras obras de los años sesenta habían incluido "investigaciones sobre materiales de construcción con recursos del país y sistemas de prefabricación flexibles" (Cárdenas, "En el cambio" 128), finalmente terminó imponiéndose "la prefabricación pesada traída de los países eurorientales, donde el frío era una razón para producir elementos en planta (y con ello) se perdían de inicio las mejores cualidades del hormigón in-situ, su monolitismo y capacidad de adoptar una variedad de formas" (Coyula, "El trinquenio amargo" 375).

La persistencia de esta mentalidad desarrollista engarza con el imaginario racionalista dominante. Aun cuando la mayoría de los profesionales que estaban en ejercicio antes de 1959 emigró, los jóvenes que se quedaron continuaron las concepciones de sus maestros. En ese sentido, cabe destacar una importante diferencia con lo ocurrido en la URss: si allá el academicismo del realismo socialista frenó a la concepción moderna por considerarla burguesa, aquí la modernidad se asumió como paradigma para la nueva arquitectura, teorizada especialmente por el arquitecto Fernando Salinas en su ensayo "La arquitectura revolucionaria del Tercer Mundo" (1967). Si en la URss el movimiento moderno, representado en el constructivismo, fue visto como una influencia capitalista "extranjerizante" y los arquitectos tradicionalistas aprovecharon esa crítica para cambiar el rumbo de la arquitectura (Cárdenas, Problemas 70-3), en Cuba se asumió una posición diametralmente opuesta: se invirtieron los términos burgueses de la modernidad arquitectónica ${ }^{15}$ para ponerla al servicio de las clases populares. Ello ocurrió no solo porque los jóvenes arquitectos habían sido al mismo tiempo "vanguardia política entre los estudiantes de arquitectura, enfrentada resueltamente a la dictadura de Batista" (Coyula, "Epílogo" 568), sino además porque el compromiso social ya existía en una parte del gremio $^{16}$.

13 Sobre el "universalismo abstracto" en la filosofía moderna, véase Grosfoguel, Ramón. "Hacia un pluri-versalismo transmoderno decolonial". Tabula Rasa 9 (2008): 199-216. Este universalismo tomará cuerpo en la "retirada de lo real", en la negación de la tradición, que experimentarán las artes y la arquitectura modernas en el siglo xx.

14 Para entonces, el hormigón armado y la prefabricación todavía lo eran.

15 Recuérdese que en 1923 Le Corbusier afirmaba, en Hacia una arquitectura: "La sociedad está llena de un violento deseo de algo que quizás obtenga o quizás no. Todo radica en eso; todo depende del esfuerzo realizado y de la atención prestada a estos síntomas alarmantes. Arquitectura o revolución. La revolución puede evitarse" (243).

16 En 1949, el arquitecto y urbanista Pedro Martínez Inclán ya abogaba por mejores condiciones y locaciones para los conjuntos residenciales obreros, como consta en el texto conocido como Carta de La Habana. 


\section{La Escuela de Artes Plásticas: ¿una arquitectura decolonial?}

¿Qué puede ser una arquitectura decolonial? Atendiendo a los aspectos indicados, sería aquella opuesta a las visiones hegemónicas, a la colonialidad del saber arquitectónico, el poder arquitectónico y el ser arquitectónico. Parafraseando la definición del semiólogo argentino Walter Mignolo sobre lo decolonial, decolonial sería aquella arquitectura cuyo punto de originación se encuentre en las concepciones espaciales subalternizadas. Frente a los antecedentes descritos, puede decirse que la Escuela de Artes Plásticas quizás no sea decolonial, pero sí apuntó a ello, al establecer una ruptura con dos puntos: con la colonialidad del saber arquitectónico y con la colonialidad del ser arquitectónico.

Sobre lo primero, se aprecia en la escuela una vocación transmoderna y decolonial tanto en su forma como en su contenido, manifiestada en la intención de poner en valor "concepciones espaciales-otras", esto es, concepciones sobre cómo habitar el espacio colectivo pensadas desde la otredad, desde la externalidad de la modernidad. Porro, considerando válidos los esquemas ancestrales de organización tribal en aldeas, concibe la escuela como una serie de recintos independientes en torno a una plaza central y cuyos componentes arquitectónicos se cargan de referencias formales muy figurativas y explícitas, que relacionan el edificio con la importancia de la mujer en aquellos sistemas no-patriarcales; claras referencias antropomórficas a senos, vaginas, ovarios que resultarán de las cúpulas, las gárgolas, las fuentes y el trazado en planta. Esta arquitectura no pretende ser una "máquina de habitar" con significación abstracta, sino un espacio nutrido de significados concretos, reivindicaciones y justicia cognitiva.

Es cierto que la obra no emerge propiamente de la epistemología afrocubana, pero está mediada por el filtro de un arquitecto que pretende ir más allá de la epistemología occidental; existe una apertura al diálogo interepistémico con las concepciones espaciales excluidas por la tradición arquitectónica moderna, una apertura impensable dentro de la lógica funcionalista, desarrollista y abstracta dominantes en la arquitectura cubana de los años cincuenta y sesenta, así como en la mayoría de la arquitectura del momento. El concepto manejado tampoco se inscribe en la lógica posmoderna ni kitsch, pues no banaliza formas del pasado. Por el contrario, se trata de un ejercicio intelectual crítico, con vocación intercultural y alto contenido simbólico: sus bóvedas catalanas, que remiten directamente a una tradición constructiva española, cobijan a una organización tribal que es clara referencia a la tradición espacial africana. Estas intenciones hacen que la Escuela de Artes Plásticas sea una obra auténtica, digna de comparar con las exploraciones contemporáneas que ocurrían en otras manifestaciones del arte, como las pinturas de Wilfredo Lam o, si se quiere, la poesía de Nicolás Guillén. Esta construcción representa una síntesis producida desde el posicionamiento en una cultura concreta (la afrocubana) proyectada hacia la universalidad.

En sintonía con lo anterior está el intento de descolonizar el ser arquitectónico, presente en la medida en que los espacios promueven una forma de ser/estar en 
relación con los demás y con el entorno ajena a los mecanismos panópticos propios de la arquitectura escolar precedente, marcada por su carácter cerrado y una distribución espacial funcional al ejercicio de la vigilancia. La libertad espacial de la escuela refleja un concepto de libertad de habitar los espacios. No es una arquitectura del control, sino de la libertad, contenedora de las ideas románticas del momento ${ }^{17}$. Curiosamente, quienes representaban la búsqueda del "hombre nuevo" y ostentaron el poder de enunciación tildaron a las Escuelas de Artes, y particularmente a Porro, de elitista y burgués.

\section{Conclusiones}

En este trabajo, hemos analizado la obra de un arquitecto desde un enfoque novedoso, que intenta aportar a la renovación de la crítica y la historiografía disciplinar al ubicarse desde fuera de la modernidad arquitectónica. Así, planteamos que en la conceptualización y construcción de la Escuela de Artes Plásticas existe un intento de dar forma arquitectónica a una concepción socioespacial subyacente en parte de la cultura nacional cubana (la procedente de las culturas africanas). Dicha búsqueda hace que la obra trascienda la esencia universalista y abstracta de la arquitectura moderna para ubicarse en la antesala de una arquitectura decolonial o, si se quiere, de la descolonización arquitectónica. En este sentido, habría que indicar que la descolonización arquitectónica no se agota en la intención de Ricardo Porro, pues implica descolonizar tanto el saber arquitectónico (desmontar los criterios hegemónicos sobre cómo hacer y valorar la arquitectura), como el ser arquitectónico (diversificar las formas de habitar el espacio arquitectónico, de relacionarse con él) y el poder arquitectónico (asumir la arquitectura como construcción colectiva y no como un designio personal), y esto último no estuvo en la vocación de su arquitecto, cuyo método sigue centrado en el trabajo del creador independiente.

\section{Referencias}

Barriendos, Joaquín. "La colonialidad del ver: hacia un nuevo diálogo visual interepistémico". Nómadas 35 (2011): 13-29. Impreso.

Cabrera Infante, Guillermo. ¡Vaya papaya!, Ramón Alejandro. París: Le Polygraphe, 1992. Impreso.

Cárdenas, Eliana. Problemas de teoría de la arquitectura. Guanajuato: Universidad de Guanajuato, 1998. Impreso.

17 Cabe señalar que este principio está presente también en el resto de las escuelas. 
---. "En el cambio de milenio: polémicas y realidades en la arquitectura cubana". Archivos de Arquitectura Antillana 5.10 (2000): 128-133. Impreso.

Carpentier, Alejo. La ciudad de las columnas. Barcelona: Lumen, 1970. Impreso.

Castro-Gómez, Santiago. "Decolonizar la universidad. La hybris del punto cero y el diálogo de saberes”. El giro decolonial. Reflexiones para una diversidad epistémica más allá del capitalismo global. Ed. Santiago Castro-Gómez y Ramón Grosfoguel. Bogotá: Siglo del Hombre, 2007. 79-92. Impreso.

Castro-Gómez, Santiago y Ramón Grosfoguel. "Prólogo. Giro decolonial, teoría crítica y pensamiento heterárquico". El giro decolonial. Reflexiones para una diversidad epistémica más allá del capitalismo global. Ed. Santiago Castro-Gómez y Ramón Grosfoguel. Bogotá: Siglo del Hombre, 2007. 9-24. Impreso.

Consuegra, Hugo. "Las Escuelas Nacionales de Arte". Arquitectura 334 (1965): 14-25. Impreso.

Coyula, Mario. "El trinquenio amargo y la ciudad distópica: autopsia de una utopía”. Cuba: contrapuntos de cultura, historia y sociedad. Ed. Francisco Scarano y Margarita Zamora. San Juan: Callejón, 2007. 361-385. Impreso.

---. "Epílogo: ¿Y después de Sert?”. De Forestier a Sert. Ciudad y arquitectura en La Habana (1925-1960). Ed. Francisco Gómez Díaz. Madrid: Abada, 2008. 565570. Impreso.

Dussel, Enrique. Hacia una filosofía política crítica. Bilbao: Desclée de Brouwer, 2001. Impreso.

Duverger, Heriberto. "De cuando las escuelas se envolvían en arco iris". Arquitectura y Urbanismo 9.2 (1988): 25-33. Impreso.

Escobar, Arturo. "Mundos y conocimientos de otro modo. El programa de investigación de modernidad/colonialidad latinoamericano". Tabula rasa 1 (2003): 51-86. Impreso.

Farrés, Yesser y Alberto Matarán. "Colonialidad territorial: para analizar a Foucault en el marco de la desterritorialización de la metrópoli. Notas desde La Habana”. Tabula rasa 16 (2012): 139-159. Impreso.

---. "Hacia una teoría urbana transmoderna y decolonial: una introducción". Polis 13.37 (2014): 339-361. Impreso.

Farrés, Yesser y Bladimir Michel. "Hacia otro enfoque en la enseñanza del proyecto de arquitectura”. Arquitectura y urbanismo 28.3 (2007): 61-67. Impreso.

Farrés, Yesser y Roberto Segre. "Cinco decenios de teoría de la arquitectura en Cuba (1963-2013) y un diálogo intergeneracional: entrevista a Roberto Segre”. ACE 8.23 (2013): 77-94. Impreso.

Fernández, J. "Una arquitectura a la imagen del hombre”. Revolución y Cultura 4 (2005): 4-12. Impreso.

Frampton, Kenneth. Historia crítica de la arquitectura moderna. Ed. Jorge Sainz. Barcelona: Gustavo Gili, 2005. Impreso.

Grosfoguel, Ramón. “Cambios conceptuales desde la perspectiva del sistema-mundo. 
Del cepalismo al neoliberalismo". Nueva Sociedad 183 (2003): 151-166. Impreso.

---. "La descolonización de la economía política y los estudios postcoloniales. Transmodernidad, pensamiento fronterizo y colonialidad global". Tabula Rasa 4 (2006): 17-48. Impreso.

---. "Hacia un pluri-versalismo transmoderno decolonial". Tabula Rasa 9 (2008): 199-216. Impreso.

---. "Izquierdas e Izquierdas Otras: entre el proyecto de la izquierda eurocéntrica y el proyecto transmoderno de la nuevas izquierdas descoloniales". Tabula Rasa 11 (2009): 9-29. Impreso.

Juventud Rebelde. "Escuelas cubanas de arte declaradas Monumento Nacional". Juventud Rebelde [La Habana, Cuba]. 19 Feb 2013. Web. 13 Mar. 2016.

Kaup, Monika. “ «Vaya Papaya!»: Cuban baroque and visual culture in Alejo Carpentier, Ricardo Porro, and Ramón Alejandro”. PMLA 124/1 (2009): 156-171. Impreso.

Kontopoulos, Kyriakos. The Logics of Social Structures. Cambridge: Cambridge University Press, 1993. Impreso.

Loomis, John. Revolution of Forms - Cuba's Forgotten Art Schools. Nueva York: Princeton Architectural Press, 1999. Impreso.

Maldonado-Torres, Nelson. "On the coloniality of being". Cultural Studies 21.2-3 (2007): 240-270. Impreso.

---. Against War. Durham/Londres: Duke University Press, 2006. Impreso

Martín, María Elena. "Arquitectura: hallar el marco poético. Entrevista con Ricardo Porro". Revolución y Cultura 5 (1996): 44-51. Impreso.

Martínez Andrade, Luis. "Hay que tomarse en serio el pensamiento crítico de los colonizados en toda su complejidad. (Entrevista a Ramón Grosfoguel)”. Metapolítica 83 (2013): 38-47.

Martínez Inclán, Pedro. Código de urbanismo. Carta de Atenas, Carta de La Habana. La Habana: Imprenta P. Fernández y Cía., 1949. Impreso.

Mignolo, Walter. "Lo nuevo y lo decolonial". Estéticas y opción decolonial. Ed. Walter Mignolo y Pedro Pablo Gómez. Bogotá: Universidad Distrital Francisco José de Caldas, 2012. Impreso.

Montaner, Josep María. Arquitectura y crítica. Barcelona: Gustavo Gili, 1999. Impreso.

Morales, Juan Luis. "Ricardo Porro entrevisto. Ciudadano del mundo". Revista Encuentro de la Cultura Cubana 32 (2004): 11-30. Impreso.

---. "Fallece en París el arquitecto cubano Ricardo Porro". El Nuevo Herald. 26 Dic. 2014. Edición matutina. Web. 3 Mar 2015.

Pizarro, María José. "En el límite de la arquitectura-paisaje: las Escuelas Nacionales de Arte de La Habana”. Tesis Doctoral. Universidad Politécnica de Madrid, 2012. <http://oa.upm.es/14906/>. Web. 3 Feb 2016.

Quijano, Aníbal. "Globalización, colonialidad del poder y democracia”. Tendencias básicas de nuestra época: globalización y democracia. Caracas: Instituto Diplomático Pedro Gual, 2001. 25-60. Impreso. 
Quijano, Aníbal e Immanuel Wallerstein. "Americanity As A Concept, Or The Americas In The Modern World-System”. International Journal of Social Sciences 134 (1992): 583-591. Impreso.

Restrepo, Eduardo y Axel Rojas. Inflexión decolonial: fuentes, conceptos y cuestionamientos. Popayán: Universidad del Cauca/Universidad Javeriana, Instituto de Estudios Sociales y Culturales Pensar, 2010. Impreso.

Saldarriaga, Alberto. Aprender arquitectura. Un manual de supervivencia. Santa Fe de Bogotá: Ed. Corona, 1996. Impreso.

Salinas, Fernando. "La arquitectura revolucionaria del Tercer Mundo". Tricontinental 1.1 (1967): 93-105. Impreso.

Santos, Boaventura de Sousa. Crítica de la razón indolente. Contra el desperdicio de la experiencia. Bilbao: Desclée de Brouwer, 2009. Impreso.

Segre, Roberto. "Los años 60 y el congreso de la UIA". Arquitectura y Urbanismo 24.3 (2003): 29-33. Impreso.

---. Arquitectura antillana del siglo xx. Bogotá y La Habana: Universidad Nacional de Colombia/Editorial Arte y Literatura, 2003. Impreso.

Segre, Roberto y Antonio Vélez. “PPor qué hablar de modelo europeo de ciudad en América Latina?”. Revista de Occidente 230-231 (2000): 11-24. Impreso.

Walsh, Catherine. "Introducción. Lo pedagógico y lo decolonial: entretejiendo caminos". Pedagogías decoloniales: prácticas insurgentes de resistir, (re)existir y (re) vivir, tomo I. Quito: Abya-Yala, 2013. Impreso.

Zevi, Bruno. Saper vedere l’architettura. Turín: Einaudi, 1948. Impreso.

Recibido: 19 marzo 2016

Aceptado: 5 septiembre 2016 